\title{
Epilepsy during pregnancy: focus on management strategies
}

\author{
This article was published in the following Dove Press journal: \\ International Journal of Women's Health \\ 19 September 2016 \\ Number of times this article has been viewed
}

\author{
Laura M Borgelt ${ }^{1}$ \\ Felecia M Hart ${ }^{2}$ \\ Jacquelyn L Bainbridge 2 \\ 'Departments of Clinical Pharmacy \\ and Family Medicine, ${ }^{2}$ Departments \\ of Clinical Pharmacy and Neurology, \\ University of Colorado Anschutz \\ Medical Campus, Skaggs School \\ of Pharmacy and Pharmaceutical \\ Sciences, Aurora, CO, USA
}

\begin{abstract}
In the US, more than one million women with epilepsy are of childbearing age and have over 20,000 babies each year. Patients with epilepsy who become pregnant are at risk of complications, including changes in seizure frequency, maternal morbidity and mortality, and congenital anomalies due to antiepileptic drug exposure. Appropriate management of epilepsy during pregnancy may involve frequent monitoring of antiepileptic drug serum concentrations, potential preconception switching of antiepileptic medications, making dose adjustments, minimizing peak drug concentration with more frequent dosing, and avoiding potentially teratogenic medications. Ideally, preconception planning will be done to minimize risks to both the mother and fetus during pregnancy. It is important to recognize benefits and risks of current and emerging therapies, especially with revised pregnancy labeling in prescription drug product information. This review will outline risks for epilepsy during pregnancy, review various recommendations from leading organizations, and provide an evidence-based approach for managing patients with epilepsy before, during, and after pregnancy.
\end{abstract}

Keywords: epilepsy, teratogens, anticonvulsants, medication therapy management

\section{Introduction}

Epilepsy is a common chronic disorder affecting approximately over one million women of childbearing age. ${ }^{1-3}$ Reproductive function can negatively impact women with epilepsy (WWE) by decreasing fertility, increasing the risk of polycystic ovary syndrome, abnormal menstrual cycles, and altered antiepileptic drug (AED) metabolism. ${ }^{2}$ For WWE who become pregnant, 24,000 babies are born each year. ${ }^{3}$ While over $90 \%$ of these women have healthy babies, there are specific concerns for WWE, in whom the disorder may significantly impact the health of the mother and the fetus. ${ }^{4}$ With numerous issues and needs to address for WWE during pregnancy, health care is often fragmented with few medical groups providing joint obstetric-epilepsy care. ${ }^{5}$ An individualized approach delivered by a team of neurologists, obstetricians, primary care doctors, nurses, and clinical pharmacists with knowledge of various aspects of epilepsy in pregnancy is needed to improve outcomes in pregnant patients with epilepsy. This article aims to provide essential knowledge and effective medication management strategies to care for WWE before, during, and after pregnancy. It is important to note that several other nonpharmacological issues may need to be addressed in WWE, such as previous obstetric and psychiatric history, but are outside the scope of this review.

\section{Risks and complications in pregnant WWE}

Although a majority of WWE (54\%-80\%) will not experience a change in seizure frequency during pregnancy, seizure frequency and severity may increase in $15 \%-32 \%$ 
of WWE as estrogen and progesterone can alter neuronal excitability and affect the seizure threshold. ${ }^{1,6-8}$ Therefore, seizure control prior to pregnancy is one of the best predictors of seizure control during pregnancy. Women who are seizurefree in the 9 months prior to pregnancy have an $84 \%-92 \%$ chance of remaining seizure-free during pregnancy on their current regimen. ${ }^{1}$

Another factor for WWE who become pregnant is an increased risk of maternal mortality. Maternal mortality is ten times higher in WWE than in those without the disorder. ${ }^{9}$ In a retrospective cohort study 69,385 WWE and 20,449,532 without epilepsy, the risk of death in WWE during delivery hospitalization was 80 per 100,000 pregnancies and was significantly higher than 6 deaths per 100,000 pregnancies in women without epilepsy (adjusted odds ratio [OR], 11.46 [95\% confidence interval [CI], 8.64-15.19]). ${ }^{10} \mathrm{WWE}$ also had increased risk of other adverse outcomes, including preeclampsia (adjusted OR, 1.59 [95\% CI, 1.54-1.63]), preterm labor (adjusted OR, 1.54 [95\% CI, 1.50-1.57]), and stillbirth (adjusted OR, 1.27 [95\% CI, 1.17-1.38]), and increased health care utilization, including an increased risk of cesarean delivery (adjusted OR, 1.40 [95\% CI, 1.38-1.42]) and prolonged length of hospital stay ( $>6$ days) among women with cesarean deliveries (adjusted OR, 2.13 [95\% CI, 2.03-2.23]) and vaginal deliveries (adjusted OR, 2.60 [95\% CI, 2.41-2.80]). ${ }^{10}$ Other obstetrical complications that have been observed in WWE include bleeding in pregnancy, excessive bleeding postpartum, preterm birth, and small for gestational age. ${ }^{11}$ A systematic review of 38 studies in low- and high-income countries found that WWE $(2,837,325$ pregnancies) had increased risks of spontaneous miscarriage (OR 1.54, 95\% CI 1.02-2.32; $I^{2}=67 \%$ ), antepartum hemorrhage (OR 1.49, 95\% CI 1.01-2.20; $I^{2}=37 \%$ ), postpartum hemorrhage (OR 1.29, 95\% CI 1.13-1.49; $I^{2}=41 \%$ ), hypertensive disorders (OR 1.37, 95\% CI 1.21-1.55; $I^{2}=23 \%$ ), induction of labor (OR 1.67, 95\% CI 1.31-2.11; $I^{2}=64 \%$ ), cesarean section (OR 1.40, 95\% CI 1.23-1.58; $I^{2}=66 \%$ ), any preterm birth ( $<37$ weeks of gestation; OR $1.16,95 \%$ CI 1.01-1.34; $I^{2}=64 \%$ ), and fetal growth restriction (OR 1.26 , 95\% CI $1.20-1.33 ; I^{2}=1 \%$ ) compared with women without epilepsy $(2,809,984$ pregnancies $) .{ }^{12}$ Outcomes that did not differ between women with and without epilepsy included early preterm birth, gestational diabetes, fetal death or stillbirth, perinatal death, or admission to neonatal intensive care.

Children who are born to WWE have a higher risk of birth defects, likely related to in utero exposure to AEDs. Specifically, WWE have a $4 \%-14 \%$ chance of giving birth to a child with a major malformation, compared with $1 \%-4 \%$ in the general population. ${ }^{2,13}$ Major malformations associated with exposure to AEDs include cleft lip and palate, ventricular septal defect, neural tube defects, and minor abnormalities that include hypertelorism, epicanthal folds, broad nasal bridge, elongated philtrum, distal digital, and nail bed hypoplasia. ${ }^{1,2}$ The risk of malformation appears to be different for individual AEDs and can be related to dose.

One of the most important issues related to birth defects caused by AED exposure is the ability of the provider to appropriately assess risks and complications that may occur. In 2014, the US Food and Drug Administration (FDA) published the "Pregnancy and Lactation Labeling Rule" (PLLR or Final Rule), which required changes to the content and format of information presented in the prescription drug labeling (eg, package insert). ${ }^{14}$ The pregnancy subsection removed the pregnancy letter categories (A, B, C, D, X) and required (rather than recommended) information about pregnancy exposure registries and now includes subheadings of risk summary, clinical considerations, and data. Other subsections that will be included in the PLLR include lactation and females and males of reproductive potential. The intention of these changes was to assist health care providers in evaluating benefit versus risk and in counseling pregnant women and nursing mothers who need to take medication and allow them to make informed and educated decisions for themselves and their children.

Therefore, the presence of epilepsy and exposure to AEDs presents a small, yet significant association with adverse outcomes in pregnancy. These increased risks and data regarding each drug should be considered when discussing reproductive health and conception planning for WWE.

\section{Management issues in the treatment of epilepsy before and during pregnancy Medication considerations}

Medication therapy is the mainstay of treatment in patients with epilepsy; however, $\sim 50 \%$ of patients will continue to have seizures following initiation of their first AED. ${ }^{15,16}$ This often leads to either switching to an alternative medication or the addition of an adjunctive AED. These treatment challenges are especially problematic in WWE who are pregnant or are planning to become pregnant. Ideally, prior to contraception, being seizure-free for at least 9-12 months is a relatively good predictor of freedom from seizure throughout the pregnancy. ${ }^{17-19}$ However, this predictor is dependent 
upon AED drug serum concentrations staying within 35\% of the preconception value throughout the pregnancy. ${ }^{20}$ This can be challenging due to the potential for significant pharmacokinetic changes during pregnancy, such as marked increases in clearance and volume of distribution. ${ }^{20}$ Several AEDs have been documented to have increases in clearance that has led to decreased serum concentrations, which has resulted in increased seizure frequency. More frequent monitoring of serum drug concentrations and patient education can be a valuable tool when managing a pregnant WWE. ${ }^{21}$

\section{Monotherapy versus polytherapy}

One important preconception goal is the utilization of medication monotherapy versus polytherapy. This recommendation is supported by the American Academy of Neurology and the American Epilepsy Society in their practice parameter update of management issues in pregnant WWE. ${ }^{1}$ It was previously thought that AED polytherapy should always be avoided during pregnancy because prior studies showed a higher rate of major congenital malformations. It was found in the North American Antiepileptic Drug Pregnancy Registry that including valproate in these regimens was a major influence on these data and exposure to other combinations of AEDs was similar to rates seen in monotherapy.22 Therefore, using specific polytherapy combinations with less teratogenic risk (eg, levetiracetam and lamotrigine) should be considered prior to initiating valproate for idiopathic or genetic generalized epilepsy.

When possible, using monotherapy prior to and during pregnancy is preferred because it can reduce the risk of long-term poor cognitive outcomes in the offspring that was associated with polytherapy. ${ }^{23-26} \mathrm{~A}$ key part of preparing a WWE for pregnancy involves trying to identify the minimum therapeutic dose (and corresponding level) that is able to control her seizures. As mentioned earlier, polytherapy has also been associated with higher malformation rates. ${ }^{27}$ There are some AEDs, such as valproate and phenobarbital, that possess more risk of causing clinical malformations and cognitive impairment than others, and the benefits rarely outweighs the risks. Additionally, some AEDs lack extensive human data and evaluation of animal data, small observational studies, and anecdotal data is needed to guide treatment decisions. Despite monotherapy offering notably lower risks during pregnancy, each individual AED possesses its own associated teratogenicity risk when used as monotherapy and should be considered on an individual patient basis (Table 1).

Table I AED pregnancy category and risk

\begin{tabular}{|c|c|c|}
\hline Drug name & $\begin{array}{l}\text { Previous FDA } \\
\text { pregnancy category }\end{array}$ & Documented pregnancy outcomes \\
\hline $\mathrm{AZA}^{42-46, \mathrm{~b}}$ & $\mathrm{C}$ & $\begin{array}{l}\text { One case of congenital glaucoma, microphthalmia, and patent ductus arteriosus } \\
\text { One case of sacrococcygeal teratoma } \\
\text { One case of metabolic complications postpartum (metabolic acidosis, } \\
\text { hyperbilirubinemia, hypocalcemia, and hypomagnesemia) } \\
\text { Animal studies: ureter and kidney abnormalities in mice; vertebral malformations } \\
\text { occurred more frequently when dose was higher in rabbits }\end{array}$ \\
\hline $\mathrm{BRV}^{47}$ & C & $\begin{array}{l}\text { There are limited amount of data in pregnant women } \\
\text { Animal studies did not detect any teratogenic potential }\end{array}$ \\
\hline $\mathrm{CBZ}^{48-53}$ & $\mathrm{D}$ & $\begin{array}{l}\text { EURAP Registry: } 2 \% \text { rate of MCM with }<400 \mathrm{mg} / \mathrm{d} \text { : neural tube defects, spina } \\
\text { bifida, hypospadias, craniofacial defects, cardiovascular malformations } \\
\text { No strong evidence of increase in } \mathrm{MCM} \text { compared to general population } \\
\text { Developmental delays }\end{array}$ \\
\hline CLB & C & $\begin{array}{l}\text { Withdrawal symptoms } \\
\text { Animal studies: neurobehavioral and immunological function defects, decreased } \\
\text { fetal body weights, and increased incidences of visceral and skeletal malformations }\end{array}$ \\
\hline $\mathrm{CZP}^{54}$ & $\begin{array}{l}D \text { (US) } \\
C \text { (AUS) }\end{array}$ & $\begin{array}{l}\text { Withdrawal symptoms } \\
\text { Animal studies: cleft palates }\end{array}$ \\
\hline Diazepam ${ }^{55-61}$ & $\mathrm{D}$ & $\begin{array}{l}\text { Congenital malformations and developmental abnormalities } \\
\text { One case of OEIS complex } \\
\text { Low birth weight } \\
\text { Withdrawal symptoms (three cases) }\end{array}$ \\
\hline Divalproex sodium (VPA) & $x$ & See valproic acid \\
\hline $\mathrm{ESL}^{62}$ & C & $\begin{array}{l}\text { Animal studies: teratogenicity, developmental delays, skeletal abnormalities, and } \\
\text { fetal growth retardation }\end{array}$ \\
\hline
\end{tabular}


Table I (Continued)

\begin{tabular}{|c|c|c|}
\hline Drug name & $\begin{array}{l}\text { Previous FDA } \\
\text { pregnancy category }\end{array}$ & Documented pregnancy outcomes \\
\hline \multirow[t]{2}{*}{ ESM $^{63-68}$} & $\begin{array}{l}\text { Not formally assigned } \\
\text { (pregnancy risk }\end{array}$ & $\begin{array}{l}\text { Cases of hemorrhage in the neonate, patent ductus arteriosus, cleft lip/palate, } \\
\text { hydrocephalus }\end{array}$ \\
\hline & factor C) & Significant increase in MCM risk when coadministered with phenobarbital \\
\hline EZG (Retigabine) & C & $\begin{array}{l}\text { Animal studies: pre- and postnatal mortality, growth deficit, developmental } \\
\text { toxicity }\end{array}$ \\
\hline $\mathrm{FBM}^{69-71}$ & C & Animal studies: higher death rate and decreased body weight \\
\hline \multirow[t]{2}{*}{$\mathrm{GBP}^{72-75}$} & $\mathrm{C}$ & One MCM out of 59 exposures (1.7\%) in Danish cohort \\
\hline & & Animal studies: delayed ossification, impaired synaptogenesis \\
\hline $\mathrm{LAC}^{76}$ & C & Animal studies: pre- and postnatal mortality, growth deficit \\
\hline \multirow[t]{4}{*}{ LTG $^{56,73,77-80}$} & $\mathrm{C}$ (immediate release) & No strong evidence of facial cleft compared to general population \\
\hline & $\mathrm{D}(\mathrm{XR})$ & EURAP study: lowest MCM rate ( $1.7 \%)$ among AED with exposure $<300 \mathrm{mg} /$ day \\
\hline & & The malformation rate was $5.2 \%$ in the Australian Registry \\
\hline & & The MCM rate was $3.7 \%$ in Denmark cohort \\
\hline \multirow[t]{4}{*}{$\mathrm{LVT}^{23,73,80-83}$} & C & Only two MCM ( $0.7 \%$, inguinal hernia and reflux requiring surgery) out of 304 \\
\hline & & first trimester exposures in UK; $2.4 \%$ MCM in US; 0 MCM out of 22 exposures in \\
\hline & & Australia; 0 MCM out of 58 exposures in Danish cohort \\
\hline & & Animal studies: structural and developmental toxicity \\
\hline \multirow[t]{2}{*}{ Lorazepam ${ }^{84,85}$} & D (US) & Withdrawal symptoms \\
\hline & $C(A \cup S)$ & Cases of anal atresia \\
\hline \multirow[t]{2}{*}{ Methsuximide $^{86}$} & Not formally assigned & Insufficient evidence regarding birth defect risk \\
\hline & factor C) & \\
\hline \multirow[t]{2}{*}{$O X C^{73,87-89}$} & $C(\mathrm{US})$ & 2.8\% MCM were seen in Danish cohort \\
\hline & $\mathrm{D}$ (AUS) & $\begin{array}{l}\text { Animal studies: developmental toxicity, malformations, embryo fetal death, } \\
\text { decreased fetal body weight }\end{array}$ \\
\hline PER $^{90}$ & C & $\begin{array}{l}\text { Animal studies: visceral abnormalities, embryo lethality, reduced fetal body } \\
\text { weight, and embryo-fetal developmental toxicity }\end{array}$ \\
\hline \multirow[t]{2}{*}{$\mathrm{PB}^{91-93}$} & $\mathrm{D}$ & Teratogenicity (first trimester): heart defects and facial clefts \\
\hline & & Withdrawal symptoms (third trimester) \\
\hline Phenytoin/Fosphenytoin $91-101$ (PHT) & $\mathrm{D}$ & $\begin{array}{l}\text { Fetal hydantoin syndrome, cases of orofacial clefts, cardiac defects, microcephaly, } \\
\text { developmental delay, malignancies (neuroblastoma) }\end{array}$ \\
\hline \multirow[t]{2}{*}{$\mathrm{PGB}^{102,103}$} & C & One case of malformation (out of 30 ) in one study \\
\hline & & Animal studies: structural and developmental abnormalities \\
\hline \multirow[t]{2}{*}{ PRM $^{104,105}$} & Not assigned & Cases of neonatal hemorrhage \\
\hline & & Animal studies: dose-related cleft palate \\
\hline RUF 106 & C & $\begin{array}{l}\text { Animal studies: decreased fetal weights and increased incidences of fetal skeletal } \\
\text { abnormalities, observed in cases of maternal toxicity }\end{array}$ \\
\hline $\mathrm{TGB}^{107}$ & C & Animal studies: high doses teratogenic effect \\
\hline \multirow[t]{5}{*}{ TPM $23,73,80,108-110$} & $\mathrm{D}$ & $\begin{array}{l}\text { Cleft lip or palate ( } 1.4 \% \text { in US, } 2.2 \% \text { in UK, both } \sim \text { ten-fold the general population), } \\
\text { hypospadias }\end{array}$ \\
\hline & & Small for gestational age (lower birth weight and shorter length): seems \\
\hline & & 1.8- to 3.3-fold more likely to happen than with lamotrigine \\
\hline & & One malformation out of 31 exposures (3.2\%) was seen in the Australian Registry \\
\hline & & 4.6\% MCM were seen in Danish cohort \\
\hline \multirow[t]{11}{*}{$\operatorname{VPA}^{23,26,53,57,80,|1|-\mid 131}$} & $\mathrm{X}$ & Strong evidence of human teratogenicity: neural tube defects, higher rate of spina \\
\hline & & bifida (I\%-2\%) than other AEDs, craniofacial defects (cleft palate), malformations \\
\hline & & of the limbs, cardiovascular malformations (atrial septal defects), hypospadias \\
\hline & & MCM reported 6\%-9\% (fourfold compared to any monotherapy) \\
\hline & & Increased risk of MCM both when used in monotherapy and polytherapy \\
\hline & & Dose-related risk of MCM (6\% under $700 \mathrm{mg} /$ day, $10 \%$ between 700 and \\
\hline & & $\mathrm{I}, 500 \mathrm{mg} /$ day, $>20 \%$ above $\mathrm{I}, 500 \mathrm{mg} /$ day) \\
\hline & & Developmental delay: lower IQ scores (verbal more than nonverbal) compared \\
\hline & & to no AED or monotherapy, increased risk of ADHD at age 6 years \\
\hline & & Withdrawal syndrome if taken during the third trimester \\
\hline & & Cases of hypoglycemia and hypothyroidism \\
\hline
\end{tabular}


Table I (Continued)

\begin{tabular}{lll}
\hline Drug name & $\begin{array}{l}\text { Previous FDA } \\
\text { pregnancy category }\end{array}$ & Documented pregnancy outcomes \\
\hline VGB $^{132,133}$ & $\mathrm{C}$ & $\begin{array}{l}\text { Cases of congenital malformations (eg, cardiac, genital, and renal defects) } \\
\text { ZNS }\end{array}$ \\
& $\mathrm{C}$ & $\begin{array}{l}\text { Two cases of visual field loss in children (6- and 7-year-old) exposed in utero } \\
\text { Small for gestational age (lower birth weight and shorter length): seems } 0.9 \text { to }\end{array}$ \\
& $2.8-$-fold more likely to happen than with lamotrigine \\
& One case of anencephaly and one case of atrial septal defect \\
\hline
\end{tabular}

Notes: a FDA pregnancy category definitions: A - Adequate and well-controlled studies have failed to demonstrate a risk to the fetus in the first trimester of pregnancy (and there is no evidence of risk in later trimesters). B - Animal reproduction studies have failed to demonstrate a risk to the fetus and there are no adequate and well-controlled studies in pregnant women. C - Animal reproduction studies have shown an adverse effect on the fetus and there are no adequate and well-controlled studies in humans, but potential benefits may warrant use of the drug in pregnant women despite potential risks. D - There is positive evidence of human fetal risk based on adverse reaction data from investigational or marketing experience or studies in humans, but potential benefits may warrant use of the drug in pregnant women despite potential risks. $X$ - Studies in animals or humans have demonstrated fetal abnormalities and/or there is positive evidence of human fetal risk based on adverse reaction data from investigational or marketing experience, and the risks involved in use of the drug in pregnant women clearly outweigh potential benefits. bUsed in epilepsy; however, not an AED.

Abbreviations: AED, antiepileptic drug; ADHD, attention-deficit hyperactivity disorder; AZA, acetazolamide; BRV, brivaracetam; CBZ, carbamazepine; CLB, clobazam; CZP, clonazepam; ESL, eslicarbazepine acetate; ESM, ethosuximide; EZG, ezogabine; FDA, Food and Drug Administration; FBM, felbamate; GBP, gabapentin; LAC, lacosamide; LTG, lamotrigine; LVT, levetiracetam; MCM, major congenital malformations; OEIS, omphalocele-exstrophy-imperforate-anus-spina bifida; OXC, oxcarbazepine; PER, perampanel; PB, phenobarbital; PGB, pregabalin; PRM, primidone; RUF, rufinamide; TGB, tiagabine; TPM, topiramate; VPA, valproic acid; VGB, vigabatrin; ZNS, zonisamide.

As expected, there is dose-dependent teratogenicity risk within individual drugs; however, this has only been documented with valproate and more recently topiramate. ${ }^{27}$ Additionally, in polytherapy, teratogenicity risks have been associated with drug combinations that were not documented when each individual drug was used as monotherapy. When used in polytherapy, the malformation rate of topiramate dramatically increases to $14.1 \%$ versus $2.4 \%$ when used as monotherapy. ${ }^{25,27}$ This was recently reported in the Australian Pregnancy Registry but had not been reported prior. ${ }^{27}$ It is important to put the risk of teratogenicity into perspective; in general, the risk of significant fetal malformation is approximately $3 \%$ if one AED is prescribed and up to approximately $17 \%$ if polytherapy is recommended. ${ }^{28,29}$ Drug teratogenicity risk should be routinely considered throughout pregnancy when treating a WWE.

Once a WWE has conceived, appropriate evaluation and counseling should continue along with frequent risk-benefit pharmacotherapy evaluations and monthly AED serum concentrations. In the US, it is common practice to recommend a level II ultrasound at 18-20 weeks gestational age for women taking AEDs during pregnancy. This is a detailed anatomic evaluation, which provides very high sensitivity for structural abnormalities affecting the fetus $(>95 \%$ for neural tube defects in most laboratories).$^{30}$ As previously discussed, abrupt discontinuation of AED is not recommended solely to minimize fetal exposure. Abrupt discontinuation of any AED possesses an increased risk of status epilepticus and sudden unexpected death in epilepsy. Due to a high risk of teratogenicity and cognitive impairment with valproate and phenobarbital, these two AEDs should never be initiated in a pregnant patient or women of childbearing potential. However, in women with difficult-to-treat seizures who are clinically stable on one of these drugs and are already pregnant upon presentation, some clinicians may opt to continue the drug throughout pregnancy as opposed to abrupt discontinuation.

One example of a newer AED that appears to have an intermediate risk of teratogenicity is topiramate. ${ }^{25,27}$ Lower teratogenic risk appears to present for lamotrigine and levetiracetam, which are commonly employed as medication therapy during pregnancy ${ }^{25,27}$ It is important to note that both lamotrigine and levetiracetam have a very high clearance in the second and third trimesters, which has led to the need for significantly higher doses, not seen in patients who are not pregnant. Serum concentrations of all AEDs should be followed on a regular basis, including a bound level for all AEDs that are highly protein bound. ${ }^{29}$

\section{Brand versus generic AEDs}

Current guidelines do not address or recommend switching from brand to generic AEDs in pregnant patients due to the possibility of disrupting the stable state of the patient by the increased risk of seizures. However, it has been shown that there was no increase in hospitalizations and all cause emergency department visits when patients switched from brand to generic lamotrigine, divalproex, and phenytoin. ${ }^{31}$ Despite this, there are often issues with the utilization of AEDs, which is why it is often recommended that AEDs not be switched from brand to generic. This is represented in incidences where brand phenytoin was switched to generic and dose adjustments and/or the addition of another AED were 
necessary. ${ }^{31}$ Furthermore, the most commonly used AED in pregnancy is lamotrigine since it is associated with the lowest risk of fetal malformations compared to other AEDs. ${ }^{23}$ Recently, a couple of FDA bioequivalence studies supported switching from brand to generic lamotrigine in patients with epilepsy. ${ }^{32,33}$ These studies did not include pregnant patients or make a recommendation for its use in this special population. Additionally, the American Epilepsy Society published a position statement regarding generic substitution of AEDs without a recommendation for patients with epilepsy who are pregnant. ${ }^{34}$ Therefore, it is currently unknown if generic substitution is appropriate in patients with epilepsy who are pregnant. $^{32,33}$

Ideally, safe and effective medication selection should occur prior to pregnancy; use of monotherapy and frequent serum AED concentrations monitoring will decrease the risk of dose-related teratogenicity and decrease the risk of complications from increased seizure frequency.

\section{Counseling and education: risk-benefit assessments and use of guidelines}

Benefit and risk assessments for WWE who want to become pregnant should begin prior to conception. Preconception planning, including adequate contraception, proper counseling, and good clinical disease management, is essential in WWE to mitigate any fetal or maternal risk. Practitioner-initiated education and counseling in women of childbearing potential should be a top priority. Common misconceptions surrounding pregnancy in WWE have led to permanent sterilization so as to not genetically pass on the disease, fear of pregnancy causing increased seizure frequency leading to poor fetal/maternal outcomes, and lack of breastfeeding. Several organizations have included recommendations of counseling and education points that should be reviewed when discussing conception and pregnancy with WWE (Table 2). These guidelines and recommendations are largely based around appropriate education and counseling, and less on medication therapy management.

There should also be a discussion about preconception folic acid supplementation and vitamin $\mathrm{K}$ supplementation at birth. There are currently no commonly accepted and consistent standards (Table 2) specific to WWE and the recommendation for folic acid. This has led to practitioners supplementing patients using their own discretion. However, in most practices in the US, WWE planning pregnancy are given the recommendation of $400 \mathrm{mcg}$ daily of folic acid. When they become pregnant, if they have no history or family history of neuronal tube defects (eg, spinal bifida) and are not

Table 2 Recommendations for epilepsy and pregnancy

\begin{tabular}{|c|c|c|c|}
\hline Topic & AAN/AES' & UK NICE guidelines ${ }^{136}$ & ETDP - EFA ${ }^{137}$ \\
\hline Year of publication & 2009 & 2012 (update 2016) & 2007 \\
\hline Counseling on & Tonic-clonic seizures: & Tonic-clonic seizures: & Tonic-clonic seizures: \\
\hline \multirow[t]{5}{*}{$\begin{array}{l}\text { seizure-induced harm } \\
\text { during pregnancy }\end{array}$} & Not mentioned & $\begin{array}{l}\text { Relatively higher risk of harm } \\
\text { to fetus }\end{array}$ & $\begin{array}{l}\text { Can particularly increase the risk of } \\
\text { brain or other injuries, congenital } \\
\text { malformations, and developmental } \\
\text { delay (verbal IQ affected by seizure } \\
\text { frequency) in the fetus }\end{array}$ \\
\hline & Status epilepticus: & Status epilepticus: & Status epilepticus: \\
\hline & Possible in $0 \%-1.8 \%$ of WWE & Can possibly occur & $\begin{array}{l}\text { Poses risks of maternal and fetal } \\
\text { survival, excellent seizure control } \\
\text { is therefore needed, particularly for } \\
\text { complex partial and tonic-clonic } \\
\text { seizures }\end{array}$ \\
\hline & SUDEP: & SUDEP: & SUDEP: \\
\hline & Not mentioned & Possible & Not mentioned \\
\hline \multirow{10}{*}{$\begin{array}{l}\text { Counseling on } \\
\text { seizure frequency } \\
\text { during pregnancy }\end{array}$} & Increase in seizure frequency: & Increase in seizure & Increase in seizure frequency: \\
\hline & Might occur in $14 \%-32 \%$ of WWE & frequency: & Occur in one-fourth to one-third of \\
\hline & & Not likely to occur & WWE \\
\hline & Seizure freedom at least 9 months & Seizure freedom at least & Seizure freedom at least \\
\hline & prior to pregnancy: & 9 months prior to pregnancy: & 9 months prior to pregnancy: \\
\hline & Probably associated with a high & Not mentioned & Not mentioned \\
\hline & likelihood (84\%-92\%) of remaining & & \\
\hline & seizure-free during pregnancy & & \\
\hline & $\begin{array}{l}\text { Frequency of tonic-clonic } \\
\text { seizures: }\end{array}$ & $\begin{array}{l}\text { Frequency of tonic-clonic } \\
\text { seizures: }\end{array}$ & $\begin{array}{l}\text { Frequency of tonic-clonic } \\
\text { seizures: }\end{array}$ \\
\hline & May affect the risk of harm to the fetus & Not mentioned & Not mentioned \\
\hline
\end{tabular}


Table 2 (Continued)

\begin{tabular}{ll}
\hline Topic & AAN/AES \\
\hline Counseling on risks & There is probably no more than a \\
for pregnant WWE & I.5-fold increased risk of premature \\
contraction, labor, or delivery, but \\
there is possibly more than a twofold \\
increase in such risk in WWE who \\
smoke \\
Probably increased risk of SGA and \\
possibly at increased risk of I-minute \\
Apgar scores of $<7$ \\
Probably no increased risk of \\
late pregnancy-related bleeding \\
complications, insufficient evidence \\
for hemorrhagic complications in the \\
newborn
\end{tabular}

Prenatal screening Not mentioned

Dose of AED

Polytherapy

Monitoring of AED serum levels

Folic acid administration
Dose of VPA and LTG should be limited since it is correlated to MCM

\section{Should be avoided:}

During the first trimester to prevent MCM

Throughout pregnancy to prevent cognitive impairment, especially when VPA is included

Should be considered routinely for LTG (seizure frequency is probably increased when $65 \%$ of target level is reached), CBZ, and PHT may be considered routinely for OXC and LVT Not enough evidence for other AED

\section{Time frame:}

Prior to conception and during pregnancy may be considered to prevent MCM

Dose:

At least $0.4 \mathrm{mg} /$ day
UK NICE guidelines ${ }^{136}$

More likely to have complications during pregnancy and labor

Pregnant women and girls who are taking AEDs should be offered a high-resolution ultrasound scan at 18-20 weeks of gestation by an appropriately trained ultrasonographer, but earlier scanning may allow MCM to be detected sooner

Lowest effective dose for each AED

\section{Should be avoided}

Recommended if seizures increase or are likely to increase Recommended if dose needs to be adjusted

Not recommended otherwise in routine

Lamotrigine and phenytoin are at risk of low serum levels

Time frame:

Before any possibility of pregnancy

Dose:

$5 \mathrm{mg} /$ day
ETDP - EFA ${ }^{137}$

In some studies, WWE have an increased risk of vaginal bleeding, hypertension, preeclampsia, antepartum hemorrhage, and cesarean delivery

Higher-than-expected rates of preterm delivery, failure to progress, and cesarean section are still evident in WWE

$95 \%$ of WWE have a safe normal delivery without a seizure; generalized epilepsy women are more likely than those with partial epilepsy to have a seizure at this time

WWE are more likely to have labor induced, abruptio placentae, cesarean sections, and maternal death around delivery (tenfold for the latter but risk still low 8/I0,000)

Ultrasound at $1 \mathrm{I}-13$ weeks is recommended to rule out neural tube defects (along with serum alphafetoprotein at 16 weeks) and other MCM

Ultrasound at 18-22 weeks to determine cardiac development, head and spine anatomy, and cleft lip or cleft palate

Seizure control with the minimum effective AED dose is the goal, minimizing fetal exposure to AED Monotherapy is preferable whenever possible, while still maintaining good seizure control VPA is most likely to induce malformations when used as polytherapy Careful monitoring of AED levels is needed throughout pregnancy AED levels should be monitored closely in the weeks following delivery since they may increase gradually LVT, OXC, and LTG showed elevated levels with days of delivery

\section{Time frame:}

Before conception and throughout pregnancy

Dose:

$0.4 \mathrm{mg} /$ day for nonpregnant women, $0.6 \mathrm{mg} /$ day for pregnant women and those contemplating pregnancy, and $0.5 \mathrm{mg} /$ day for lactating women. Many epileptologists recommend higher doses (0.8-4 mg/day) for women with epilepsy. However, for women with a family history of a neural tube defect, $4 \mathrm{mg} /$ day is the recommended dosage 
Table 2 (Continued)

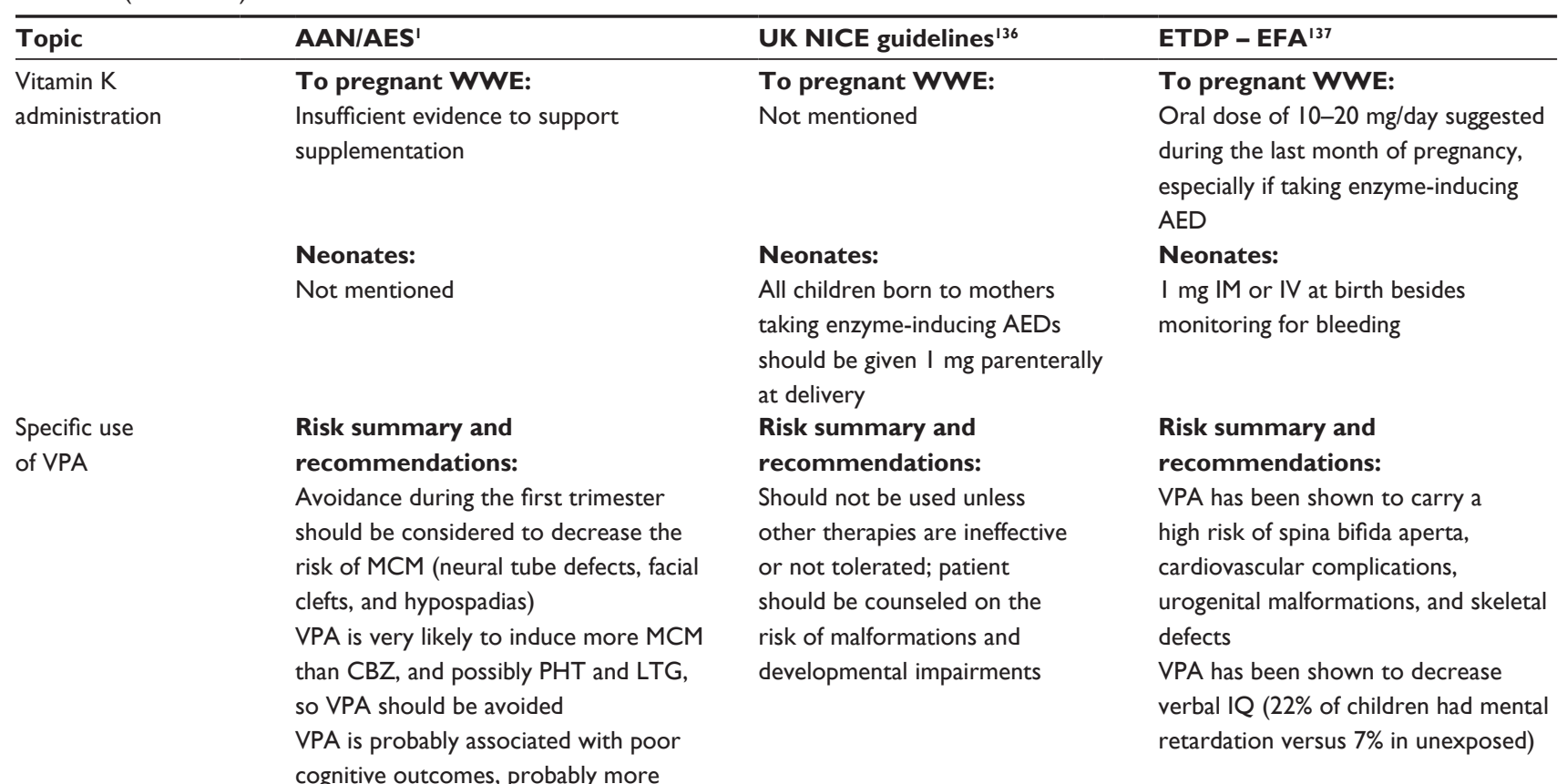

than CBZ and possibly more than PHT,

so VPA should be avoided

Dose-dependent risk:

Not mentioned

Dose-dependent risk:

Greater risk with doses $>800$

mg/day

\section{Polytherapy:}

Higher evidence of such risk if VPA is

taken as part of polytherapy AED

Specific use of other AED

\section{Polytherapy: \\ Greater risk}

Older AED:

Not mentioned

\section{Older AED:}

CBZ, PHT, PB: avoidance may be considered to reduce the risk of cleft palate ( $\mathrm{PHT}$ and $\mathrm{CBZ}$ ), cardiac malformations (PB), and poor cognitive outcomes (PHT and PB)

\section{Newer AED:}

Not enough data to assess teratogenicity and make recommendations

\section{Dose-dependent risk:}

VPA is most likely to induce

malformations when used above doses of $1,000 \mathrm{mg} /$ day; decrease in verbal IQ is dose-dependent

Polytherapy:

Not mentioned

\section{Older AED:}

Barbiturates have been found to be associated with MCM

PHT has been associated with facial clefts, congenital heart, and urogenital defects

CBZ has been associated with neural tube defects, heart defects, hypospadias, hip dislocations, and inguinal hernia

Newer AED:

Lamotrigine has the most data available at this time, with possibly no substantially increased risk of MCM Preliminary studies have found a good pregnancy safety profile with levetiracetam, but more data are needed

Abbreviations: AED, antiepileptic drug; AAN, American Academy of Neurology; AES, American Epilepsy Society; CBZ, carbamazepine; ETPD - EFA, Epilepsy Therapy Development Project - Epilepsy Foundation of America; IM, intramuscular; LTG, lamotrigine; LVT, levetiracetam; MCM, major congenital malformations; OXC, oxcarbazepine; PB, phenobarbital; PHT, phenytoin; SUDEP, sudden unexpected death in epilepsy; VPA, valproic acid; WWE, women with epilepsy.

on an AED commonly associated with neuronal tube defects, they should be on folic acid 400-800 mcg daily. If the women has a history or family history of neuronal tube defects, it is generally recommended that they be started on folic acid $4 \mathrm{mg} 1$ month prior to conception and continue throughout their pregnancy. Some practitioners will use $4 \mathrm{mg}$ per day of folic acid if a women is pregnant and on an AED that has been associated with neuronal tube defects (ie, valproic acid, carbamazepine, and gabapentin) in the absence of a history or family history of spinal bifida. If a woman has yet to 
conceive, and is willing to optimize pharmacotherapy prior to conception, a medication review should be done to make sure that she is not on valproate or any other potentially teratogenic medication (all medications in regimen). An attempt to ensure she is on the least number of AEDs at the lowest effective doses is also warranted.

The risk of passing epilepsy to the child is very low; however, in specific cases, there is a risk of idiopathic generalized epilepsy, which is $\sim 5 \%-20 \%$ (one affected first-degree relative) and $>25 \%$ (two first-degree relatives) affected. The overall risk of a mother passing on idiopathic generalized epilepsy is $9 \%-12 \%{ }^{28,35}$

\section{Overview on the current and emerging therapies}

Until recently, it was generally accepted that the newer AEDs were as effective as the older first-generation AEDs to prevent seizure. Recent data from the Australian Pregnancy Registry revealed that newer AEDs, such as topiramate and lamotrigine, were associated with increased seizure frequency during pregnancy; however, this was not statistically significant. ${ }^{27}$ This observational trend does warrant further AED efficacy studies in the pregnancy setting.

The knowledge we have on risks during pregnancy for WWE taking newer and emerging therapies is very limited and is mostly based on Phase III premarketing clinical trials; this needs further assessment. Such an assessment will likely be based on data provided by various pregnancy and epilepsy registries, such as the North American AED Pregnancy Registry, the Australian Pregnancy Register for Antiepileptic Medication, the UK Epilepsy and Pregnancy Register, and The International Registry of AED and Pregnancy. Table 3 lists websites to access these pregnancy registries.

The International Registry of AED and Pregnancy was originally European-based and created in 1999 by a consortium of independent research groups, and later extended

Table 3 Websites for various pregnancy registries

\begin{tabular}{ll}
\hline Name of pregnancy registry & Website \\
\hline The North American AED & www.aedpregnancyregistry.org/ \\
Pregnancy Registry & www.epilepsy.org.au/research/ \\
Australian Pregnancy Register & $\underline{\text { australian-pregnancy-register }}$ \\
for Women on Antiepileptic & www.epilepsyandpregnancy.co.uk \\
Medication & \\
UK Epilepsy and Pregnancy & www.eurapinternational.org \\
Register & \\
The International Registry of & \\
AED and Pregnancy (EURAP) &
\end{tabular}

Abbreviation: AED, antiepileptic drug. to 42 countries in Europe, Oceania, Asia, Latin America, and Africa. It is a large prospective observation study for women taking AEDs while pregnant, as it includes data obtained from other registries, including the Australian and the UK Register, but not the North American AED Pregnancy Registry. In the International Registry of AED and Pregnancy, all women taking AEDs at conception are eligible for inclusion whether the indication for treatment is epilepsy or other disorders. To avoid selection bias, only pregnancies enrolled before fetal outcome are known and within 16 weeks of gestation contribute to the prospective study. The primary objective is to compare the safety of different AEDs during pregnancy with respect to the risk of birth defects. Secondary objectives of the study are to establish the pattern of major malformations associated with AED, evaluate dose-effect relationships, and delineate drug-specific syndromes.

Similarly, in the North American Registry, the major objective is to obtain and publish information on the frequency of major malformations, such as heart defects, spina bifida, and cleft lip, among infants whose mothers had taken one or more AEDs to prevent seizures or to treat any other medical condition. It is also a prospective study, therefore, only findings in women who have enrolled before having any prenatal screening are used, to avoid bias of retrospective data. If a patient enrolls, a phone interview will be conducted at enrollment, at 7 months of gestation, then after delivery.

Enrollment in pregnancy registries is voluntary and at the discretion of the patient and/or provider (depending on the specific registry). While the management of pregnant WWE should include counseling on risks of various AEDs, women taking newer AEDs and emerging therapies with very little information regarding potential risks and birth defects should consider collaborating with their health care providers to enroll into a registry. Indeed, the success of registries greatly depends on patients' enthusiasm, putting provider and pharmacist counseling at the center of care of pregnant WWE. Counseling regarding registry participation may be included in a specialty pharmacy program and/or be part of multidisciplinary approaches (with physicians, nurses, and pharmacists) for the care of pregnant WWE. Such approaches have proven efficacious in multiple sclerosis for adherence to disease-modifying therapies and may improve patient adherence to pregnancy registries. ${ }^{36,37}$ A specialty pharmacist in the ambulatory care neurology team may enhance patient education efficacy and recommendations from a clinical pharmacy specialist should be implemented into clinical decisions; more studies should be conducted to verify this hypothesis. 


\section{Approach to WWE after pregnancy}

Issues related to breastfeeding and epilepsy medications are outside the scope of this article; however, it is important for providers to collaborate with the patient after pregnancy so that AED medications are continued effectively and the most appropriate contraception can be provided. Once an infant is born, the AEDs taken by the mother need to be converted back to baseline dosage(s) due to the immediate changes in volume of distribution and protein binding after labor and delivery. ${ }^{38}$ Additionally, it may be necessary for providers to communicate with each other to ensure that patients have highly effective contraception that is compatible with their antiepileptic treatment and to avoid unintended pregnancies, which put patients at high risk of poor outcomes. The Center for Disease Control and Prevention has published the United States Medical Eligibility Criteria to assist health care providers when counseling women, men, and couples about contraceptive method choice. ${ }^{39}$ Specifically for WWE, the United States Medical Eligibility Criteria provides guidance on the safety of contraceptive method use with epilepsy and specific AEDs to avoid drug interactions that may decrease contraceptive efficacy. Revised recommendations were published for women in the immediate postpartum period $(<42$ days) regarding the use of combined hormonal contraceptives. ${ }^{40}$ Additionally, one of the quality measures developed by the American Academy of Neurology includes counseling for women of childbearing potential (12-44 years) with epilepsy. ${ }^{41}$ This measure is one of seven measures intended to facilitate quality improvement activities by recommending that providers give counseling at least once a year about how epilepsy and its treatment may affect contraception or pregnancy and should include a discussion about folic acid supplementation, contraception, potential antiseizure medications effect(s) on pregnancy, safe pregnancies, and breastfeeding.

\section{Conclusion}

WWE who desire pregnancy or become pregnant warrant special consideration and attention. These women have an increased risk of mortality and complications during pregnancy and labor including vaginal bleeding, preeclampsia, premature delivery, and cesarean delivery. Children who are born to WWE have a two- to threefold higher risk of major congenital malformations compared to the general population, which is likely related to in utero exposure to AEDs. The recent changes in pregnancy labeling by the FDA will allow for more critical evaluation by physicians, nurses and pharmacists regarding potential risks to mothers and their children, which will encourage shared treatment decisions.

Medication management issues include choosing initial therapy for WWE of childbearing potential with lower teratogenic potential, routinely monitoring for efficacy, and selecting monotherapy regimens when possible. Valproate is the drug with the most evidence for inducing major malformations and impairment and should be avoided during pregnancy, either as monotherapy or polytherapy. Data suggest that polytherapy with AEDs other than valproate (eg, lamotrigine and levetiracetam in combination) are as safe as monotherapy. Lamotrigine has the most evidence among newer AED of safest use during pregnancy, but possibly has still more risks of malformations than the general population. Topiramate showed intermediate risk of malformations with facial/palate cleft outcomes among the newer AEDs. Switching brand to generic AED is not recommended based on precaution principle, even though hospitalization rates were not increased when doing so. Finally, folic acid supplementation is recommended in WWE before conception and throughout pregnancy at a minimum dose of $0.4 \mathrm{mg} /$ day (4 mg/day if family history of neural tube defect, or on valproic acid, carbamazepine, or gabapentin).

Seizure frequency is not likely to increase during pregnancy, and being free of seizure 9-12 months prior to pregnancy is a good predictor of freedom from seizure during pregnancy. This success is largely dependent on AED serum concentrations, which should be monitored closely prior to and throughout pregnancy. Seizure control with the lowest effective dose of AED should be the goal and anticipated ahead of conception.

Limited data on newer and emerging AED suggest that international epilepsy and pregnancy registries are promising tools to prospectively assess birth defect risks. These registries may also be beneficial for tracking impact of older AEDs that were assigned the former FDA pregnancy category $\mathrm{C}$ where evidence has been lacking. It is important to encourage patient and/or provider participation in these registries to obtain important information about fetal abnormalities and dose-effect relationships.

Given the many facets of caring for WWE before, during, and after pregnancy, a collaborative, multidisciplinary approach is needed. The neurologists, obstetricians, primary care doctors, clinical pharmacists, and nurses have key roles in managing epilepsy and complex medication regimens as well as providing effective counseling and education regarding the benefits and risks involved with pregnancy 
in WWE. Available resources provide knowledge and tools for effective medication management strategies to care for WWE before, during, and after pregnancy.

\section{Acknowledgments}

The authors would like to acknowledge Kimberly Uweh, PharmD Candidate and Jean-xavier Peyronnet, PharmD for their assistance with background research and comments.

\section{Disclosure}

The authors report no conflicts of interest in this work.

\section{References}

1. Harden CL, Meador KJ, Pennell PB, et al. Practice parameter update: management issues for women with epilepsy - focus on pregnancy (an evidence-based review): teratogenesis and perinatal outcomes: report of the Quality Standards Subcommittee and Therapeutics and Technology Assessment Subcommittee of the American Academy of Neurology and American Epilepsy Society. Neurology. 2009;73(2):133-141.

2. Morrell MJ. Epilepsy in women. Am Fam Physician. 2002;66(8): 1489-1494.

3. Epilepsy Foundation. Risks during pregnancy; 2014. Available from: http://www.epilepsy.com/learn/impact/reproductive-risks/risks-duringpregnancy. Accessed June 19, 2016.

4. Epilepsy Foundation. Epilepsy and pregnancy; 2014. Available from: http://www.epilepsy.com/information/women/epilepsy-and-pregnancy. Accessed June 19, 2016.

5. Fairgrieve SD, Jackson M, Jonas $\mathrm{P}$, et al. Population based, prospective study of the care of women with epilepsy in pregnancy. BMJ. 2000; 321(7262):674-675.

6. Cagnetti C, Lattanzi S, Foschi N, Provinciali L, Silvestrini M. Seizure course during pregnancy in catamenial epilepsy. Neurology. 2014;83(4): 339-344.

7. Battino D, Tomson T, Bonizzoni E, et al. Seizure control and treatment changes in pregnancy: observations from the EURAP epilepsy pregnancy registry. Epilepsia. 2013;54(9):1621-1627.

8. La Neve A, Boero G, Francavilla T, Plantamura M, De Agazio G, Specchio LM. Prospective, case-control study on the effect of pregnancy on seizure frequency in women with epilepsy. Neurol Sci. 2015; 36(1):79-83.

9. Edey S, Moran N, Nashef L. SUDEP and epilepsy-related mortality in pregnancy. Epilepsia. 2014;55(7):e72-e74.

10. MacDonald SC, Bateman BT, McElrath TF, Hernandez-Diaz S. Mortality and morbidity during delivery hospitalization among pregnant women with epilepsy in the United States. JAMA Neurol. 2015; 72(9):981-988.

11. Borthen I. Obstetrical complications in women with epilepsy. Seizure. 2015;28:32-34.

12. Viale L, Allotey J, Cheong-See F, et al. Epilepsy in pregnancy and reproductive outcomes: a systematic review and meta-analysis. Lancet. 2015;386(10006):1845-1852.

13. Tomson T, Xue H, Battino D. Major congenital malformations in children of women with epilepsy. Seizure. 2015;28:46-50.

14. Food and Drug Administration. Pregnancy and lactation labeling (drugs) final rule; 2014. Available from: http:/www.fda.gov/Drugs/ DevelopmentApprovalProcess/DevelopmentResources/Labeling/ ucm093307.htm. Accessed June 19, 2016.

15. Kwan P, Brodie MJ. Epilepsy after the first drug fails: substitution or add-on? Seizure. 2000;9(7):464-468.

16. Stephen LJ, Brodie MJ. Seizure freedom with more than one antiepileptic drug. Seizure. 2002;11(6):349-351.
17. Gjerde IO, Strandjord RE, Ulstein M. The course of epilepsy during pregnancy: a study of 78 cases. Acta Neurol Scand. 1988;78(3):198-205.

18. Tomson T, Lindbom U, Ekqvist B, Sundqvist A. Epilepsy and pregnancy: a prospective study of seizure control in relation to free and total plasma concentrations of carbamazepine and phenytoin. Epilepsia. 1994;35(1):122-130.

19. Vajda FJ, Hitchcock A, Graham J, O’Brien T, Lander C, Eadie M. Seizure control in antiepileptic drug-treated pregnancy. Epilepsia. 2008; 49(1):172-176.

20. Reisinger TL, Newman M, Loring DW, Pennell PB, Meador KJ. Antiepileptic drug clearance and seizure frequency during pregnancy in women with epilepsy. Epilepsy Behav. 2013;29(1):13-18.

21. Shrestha A, Wong PS, Bainbridge PS. Bridging the knowledge gap in women with epilepsy of childbearing potential: impact of a multidisciplinary counseling and prenatal care clinic. Presented at: Program and abstracts of the 69th Annual Meeting of the American Epilepsy Society; December 4-8, 2015; Philadelphia, PA; Abstract 1.342.

22. Holmes LB, Mittendorf R, Shen A, Smith CR, Hernandez-Diaz S. Fetal effects of anticonvulsant polytherapies: different risks from different drug combinations. Arch Neurol. 2011;68(10):1275-1281.

23. Hernandez-Diaz S, Smith CR, Shen A, et al. Comparative safety of antiepileptic drugs during pregnancy. Neurology. 2012;78(21):1692-1699.

24. Maheshwari A, Athale S, Lekhra OP. Comparative safety of antiepileptic drugs during pregnancy. Neurology. 2013;80(7):689.

25. Meador KJ. Epilepsy: pregnancy in women with epilepsy - risks and management. Nat Rev Neurol. 2014;10(11):614-616.

26. Jentink J, Loane MA, Dolk H, et al. Valproic acid monotherapy in pregnancy and major congenital malformations. N Engl J Med. 2010; 362(23):2185-2193.

27. Vajda FJ, O'Brien T, Lander C, Graham J, Eadie M. The efficacy of the newer antiepileptic drugs in controlling seizures in pregnancy. Epilepsia. 2014;55(8):1229-1234.

28. Vajda F, Lander C, O'Brien T, et al. Australian pregnancy registry of women taking antiepileptic drugs. Epilepsia. 2004;45:1466.

29. Crawford P. Best practice guidelines for the management of women with epilepsy. Epilepsia. 2005;46(Suppl 9):117-124.

30. Gerard EE, Meador KJ. Managing epilepsy in women. Continuum (Minneap Minn). 2016;22(1):204-226.

31. Erickson SC, Le L, Ramsey SD, et al. Clinical and pharmacy utilization outcomes with brand to generic antiepileptic switches in patients with epilepsy. Epilepsia. 2011;52(7):1365-1371.

32. Ting TY, Jiang W, Lionberger R, et al. Generic lamotrigine versus brandname Lamictal bioequivalence in patients with epilepsy: a field test of the FDA bioequivalence standard. Epilepsia. 2015;56(9):1415-1424.

33. Privitera MD, Welty TE, Gidal BE, et al. Generic-to-generic lamotrigine switches in people with epilepsy: the randomised controlled EQUIGEN trial. Lancet Neurol. 2016;15(4):365-372.

34. Vossler D, Anderson G, Bainbridge J. AES Position Statement on Generic Substitution of Antiepileptic Drugs. Epilepsy Curr. 2016;16(3): 209-211.

35. Berkovic SF, Howell RA, Hay DA, Hopper JL. Epilepsies in twins: genetics of the major epilepsy syndromes. Ann Neurol. 1998;43(4): $435-445$.

36. Hanson RL, Habibi M, Khamo N, Abdou S, Stubbings J. Integrated clinical and specialty pharmacy practice model for management of patients with multiple sclerosis. Am J Health Syst Pharm. 2014; 71(6):463-469.

37. Habibi M, Kuttab HM. Management of multiple sclerosis and the integration of related specialty pharmacy programs within health systems Am J Health Syst Pharm. 2016;73(11):811-819.

38. Anderson GD. Using pharmacokinetics to predict the effects of pregnancy and maternal-infant transfer of drugs during lactation. Expert Opin Drug Metab Toxicol. 2006;2(6):947-960.

39. Centers for Disease Control and Prevention. U.S. medical eligibility criteria for contraceptive use, 2010. MMWR Recomm Rep. 2010; 59(RR-4):1-86. 
40. Centers for Disease Control and Prevention. Update to CDC's U.S. medical eligibility criteria for contraceptive use, 2010: revised recommendations for the use of contraceptive methods during the postpartum period. MMWR Morb Mortal Wkly Rep. 2011;60(26):878-883.

41. Fountain NB, Van Ness PC, Bennett A, et al. Quality improvement in neurology: epilepsy update quality measurement set. Neurology. 2015;84(14):1483-1487.

42. Nakatsuka T, Komatsu T, Fujii T. Axial skeletal malformations induced by acetazolamide in rabbits. Teratology. 1992;45(6):629-636.

43. Worsham F Jr, Beckman EN, Mitchell EH. Sacrococcygeal teratoma in a neonate. Association with maternal use of acetazolamide. JAMA. 1978;240(3):251-252.

44. McBride WG. The teratogenic action of drugs. Med J Aust. 1963;2: 689-692.

45. Miller TA, Scott WJ Jr. Abnormalities in ureter and kidney development in mice given acetazolamide-amiloride or dimethadione (DMO) during embryogenesis. Teratology. 1992;46(6):541-550.

46. Merlob P, Litwin A, Mor N. Possible association between acetazolamide administration during pregnancy and metabolic disorders in the newborn. Eur J Obstet Gynecol Reprod Biol. 1990;35(1):85-88.

47. Briviact ${ }^{\mathbb{E}}$ [package insert]. Smyrna, GA: UCB, Inc; 2016.

48. Tegretol ${ }^{\circledR}$ [package insert]. East Hanover, NJ: Novartis Pharmaceuticals Corporation; 2015.

49. Jones KL, Lacro RV, Johnson KA, Adams J. Pattern of malformations in the children of women treated with carbamazepine during pregnancy. N Engl J Med. 1989;320(25):1661-1666.

50. Waters CH, Belai Y, Gott PS, Shen P, De Giorgio CM. Outcomes of pregnancy associated with antiepileptic drugs. Arch Neurol. 1994; 51(3):250-253.

51. Jentink J, Dolk H, Loane MA, et al. Intrauterine exposure to carbamazepine and specific congenital malformations: systematic review and case-control study. BMJ. 2010;341:c6581.

52. Werler MM, Ahrens KA, Bosco JL, et al. Use of antiepileptic medications in pregnancy in relation to risks of birth defects. Ann Epidemiol. 2011;21(11):842-850.

53. Tomson T, Battino D, Bonizzoni E, et al. Dose-dependent risk of malformations with antiepileptic drugs: an analysis of data from the EURAP epilepsy and pregnancy registry. Lancet Neurol. 2011;10:609-617.

54. Clonazepam [package insert]. Morgantown, WV: Mylan Pharmaceuticals Inc; 2014.

55. Valium ${ }^{\circledR}$ [package insert]. Nutley, NJ: Roche Laboratories; 2008.

56. Rementeria JL, Bhatt $\mathrm{K}$. Withdrawal symptoms in neonates from intrauterine exposure to diazepam. J Pediatr. 1977;90(1):123-126.

57. Koren G, Pastuszak A, Ito S. Drugs in pregnancy. N Engl J Med. 1998; 338(16):1128-1137.

58. Rothman KJ, Fyler DC, Goldblatt A, Kreidberg MB. Exogenous hormones and other drug exposures of children with congenital heart disease. Am J Epidemiol. 1979;109(4):433-439.

59. Haram K. "Floppy infant syndrome" and maternal diazepam. Lancet. 1977;2(8038):612-613.

60. Czeizel AE, Szegal BA, Joffe JM, Racz J. The effect of diazepam and promethazine treatment during pregnancy on the somatic development of human offspring. Neurotoxicol Teratol. 1999;21(2):157-167.

61. Lizcano-Gil LA, Garcia-Cruz D, Sanchez-Corona J. Omphaloceleexstrophy-imperforate-anus-spina bifida (OEIS) complex in a male prenatally exposed to diazepam. Arch Med Res. 1995;26(1):95-96.

62. Aptiom ${ }^{\circledR}$ [package insert]. Marlborough, MA: Sunovion Pharmaceuticals Inc; 2015

63. Zarontin ${ }^{\circledR}$ [package insert]. Morris Plains, NJ: Parke-Davis; 2009.

64. Nakane Y, Okuma T, Takahashi R, et al. Multi-institutional study on the teratogenicity and fetal toxicity of antiepileptic drugs: a report of a collaborative study group in Japan. Epilepsia. 1980;21(6):663-680.

65. Fabro S, Brown NA. Teratogenic potential of anticonvulsants. N Engl J Med. 1979;300(22):1280-1281.

66. From the NIH: anticonvulsants found to have teratogenic potential. JAMA. 1981;245(1):36.
67. Koup JR, Rose JQ, Cohen ME. Ethosuximide pharmacokinetics in a pregnant patient and her newborn. Epilepsia. 1978;19(6):535-539.

68. Samren EB, van Duijn CM, Koch S, et al. Maternal use of antiepileptic drugs and the risk of major congenital malformations: a joint European prospective study of human teratogenesis associated with maternal epilepsy. Epilepsia. 1997;38(9):981-990.

69. Felbatol ${ }^{\circledR}$ [package insert]. Somerset, NJ: MEDA Pharmaceuticals Inc; 2011.

70. Adusumalli VE, Yang JT, Wong KK, Kucharczyk N, Sofia RD. Felbamate pharmacokinetics in the rat, rabbit, and dog. Drug Metab Dispos. 1991;19(6):1116-1125.

71. Wagner ML. Felbamate: a new antiepileptic drug. Am J Hosp Pharm. 1994;51(13):1657-1666.

72. Neurontin ${ }^{\circledR}$ [package insert]. New York, NY: Parke-Davis; 2015.

73. Molgaard-Nielsen D, Hviid A. Newer-generation antiepileptic drugs and the risk of major birth defects. JAMA. 2011;305(19):1996-2002.

74. Eroglu C, Allen NJ, Susman MW, et al. Gabapentin receptor alpha2delta-1 is a neuronal thrombospondin receptor responsible for excitatory CNS synaptogenesis. Cell. 2009;139(2):380-392.

75. Picchietti DL, Hensley JG, Bainbridge JL, et al. Consensus clinical practice guidelines for the diagnosis and treatment of restless legs syndrome/Willis-Ekbom disease during pregnancy and lactation. Sleep Med Rev. 2015;22:64-77.

76. Vimpat ${ }^{\mathbb{E}}$ [package insert]. Symrna, GA: UCB Pharma Inc; 2014.

77. Lamictal ${ }^{\circledR}$ [package insert]. Research Triangle Park, NC: GlaxoSmithKline; 2010.

78. Dolk H, Wang H, Loane M, et al. Lamotrigine use in pregnancy and risk of orofacial cleft and other congenital anomalies. Neurology. 2016; 86(18):1716-1725

79. Meador KJ, Penovich P. What is the risk of orofacial clefts from lamotrigine exposure during pregnancy? Neurology. 2008;71(10):706-707.

80. Vajda FJ, Graham J, Roten A, Lander CM, O’Brien TJ, Eadie M. Teratogenicity of the newer antiepileptic drugs - the Australian experience. J Clin Neurosci. 2012;19(1):57-59.

81. Keppra ${ }^{\circledR}$ [package insert]. Smyrna, GA: UCB Pharma Inc; 2009.

82. Tomson T, Palm R, Kallen K, et al. Pharmacokinetics of levetiracetam during pregnancy, delivery, in the neonatal period, and lactation. Epilepsia. 2007;48(6):1111-1116.

83. Mawhinney E, Craig J, Morrow J, et al. Levetiracetam in pregnancy: results from the UK and Ireland epilepsy and pregnancy registers. Neurology. 2013;80(4):400-405.

84. Ativan ${ }^{\circledR}$ [package insert]. Philadelphia, PA: Biovail Pharmaceuticals, Inc; 2007.

85. Bonnot O, Vollset SE, Godet PF, D'Amato T, Robert E. Maternal exposure to lorazepam and anal atresia in newborns: results from a hypothesis-generating study of benzodiazepines and malformations. J Clin Psychopharmacol. 2001;21(4):456-458.

86. Celontin ${ }^{\circledR}$ [package insert]. New York, NY: Parke-Davis; 2013.

87. Oxtellar $\mathrm{XR}^{\circledR}$ [package insert]. Rockville, MD: Supernus Pharmaceuticals Inc; 2012.

88. Trileptal ${ }^{\circledR}$ [package insert]. East Hanover, NJ: Novartis Pharmaceuticals; 2014.

89. Pienimaki P, Lampela E, Hakkola J, Arvela P, Raunio H, Vahakangas K. Pharmacokinetics of oxcarbazepine and carbamazepine in human placenta. Epilepsia. 1997;38(3):309-316.

90. Fycompa ${ }^{\circledR}$ [package insert]. Teaneck, NJ: Eisai Inc; 2015.

91. Kallen B, Robert E, Mastroiacovo P, Martinez-Frias ML, Castilla EE, Cocchi G. Anticonvulsant drugs and malformations is there a drug specificity? Eur J Epidemiol. 1989;5(1):31-36.

92. Anderson RC. Cardiac defects in children of mothers receiving anticonvulsant therapy during pregnancy. J Pediatr. 1976;89(2):318-319.

93. Annegers JF, Hauser WA, Elveback LR, Anderson VE, Kurland LI. Congenital malformations and seizure disorders in the offspring of parents with epilepsy. Int J Epidemiol. 1978;7(3):241-247.

94. Dilantin ${ }^{\circledR}$ [package insert]. New York, NY: Parke-Davis; 2016.

95. Cerebyx ${ }^{\circledR}$ [package insert]. New York, NY: Pfizer Labs; 2016. 
96. Dam M, Christiansen J, Munck O, Mygind KI. Antiepileptic drugs: metabolism in pregnancy. Clin Pharmacokinet. 1979;4(1):53-62.

97. Knott C, Williams CP, Reynolds F. Phenytoin kinetics during pregnancy and the puerperium. Br J Obstet Gynaecol. 1986;93(10): 1030-1037.

98. Kochenour NK, Emery MG, Sawchuk RJ. Phenytoin metabolism in pregnancy. Obstet Gynecol. 1980;56(5):577-582.

99. Bardy AH, Hiilesmaa VK, Teramo K, Granstrom ML. Teratogenic risks of antiepileptic drugs. Br Med J (Clin Res Ed). 1981;283(6303): 1405-1406.

100. Lander CM, Smith MT, Chalk JB, et al. Bioavailability and pharmacokinetics of phenytoin during pregnancy. Eur J Clin Pharmacol. 1984;27(1):105-110.

101. Monson RR, Rosenberg L, Hartz SC, Shapiro S, Heinonen OP, Slone D. Diphenylhydantoin and selected congenital malformations. $N$ Engl $J$ Med. 1973;289(20):1049-1052.

102. Lyrica ${ }^{\circledR}$ [package insert]. New York, NY: Parke-Davis; 2016.

103. Veiby G, Daltveit AK, Engelsen BA, Gilhus NE. Fetal growth restriction and birth defects with newer and older antiepileptic drugs during pregnancy. J Neurol. 2014;261(3):579-588.

104. Mysoline ${ }^{\circledR}$ [package insert]. Aliso Viejo, CA: Valeant Pharmaceuticals; 2009.

105. Myhre SA, Williams R. Teratogenic effects associated with maternal primidone therapy. J Pediatr. 1981;99(1):160-162.

106. Banzel ${ }^{\circledR}$ [package insert]. Woodcliff Lake, NJ: Eisai Inc; 2015.

107. Gabitri ${ }^{\mathbb{E}}$ [package insert]. North Wales, PA: Teva Pharmaceuticals; 2015.

108. Topamax ${ }^{\circledR}$ [package insert]. Titusville, NJ: Ortho Pharmaceutical Corporation; 2005.

109. Hernandez-Diaz S, Mittendorf R, Smith CR, et al. Association between topiramate and zonisamide use during pregnancy and low birth weight. Obstet Gynecol. 2014;123(1):21-28.

110. Hunt S, Russell A, Smithson WH, et al. Topiramate in pregnancy: preliminary experience from the UK Epilepsy and Pregnancy Register. Neurology. 2008;71(4):272-276.

111. Depakene ${ }^{\circledR}$ [package insert]. North Chicago, IL: AbbVie Inc; 2016.

112. Christianson AL, Chesler N, Kromberg JG. Fetal valproate syndrome: clinical and neuro-developmental features in two sibling pairs. Dev Med Child Neurol. 1994;36(4):361-369.

113. Aulthouse AL, Hitt DC. The teratogenic effects of valproic acid in human chondrogenesis in vitro. Teratology. 1994;49(3):208-217.

114. Thurston JH, Hauhart RE. Vitamins to prevent neural-tube defects. N Engl J Med. 1993;328(22):1641-1642.

115. Jager-Roman E, Deichl A, Jakob S, et al. Fetal growth, major malformations, and minor anomalies in infants born to women receiving valproic acid. J Pediatr. 1986;108(6):997-1004.

116. Boussemart T, Bonneau D, Levard G, Berthier M, Oriot D. Omphalocele in a newborn baby exposed to sodium valproate in utero. Eur J Pediatr. 1995;154(3):220-221.

117. Hubert A, Bonneau D, Couet D, Berthier M, Oriot D, Larregue M. Aplasia cutis congenita of the scalp in an infant exposed to valproic acid in utero. Acta Paediatr. 1994;83(7):789-790.

118. Laegreid L, Kyllerman M, Hedner T, Hagberg B, Viggedahl G. Benzodiazepine amplification of valproate teratogenic effects in children of mothers with absence epilepsy. Neuropediatrics. 1993;24(2):88-92.
119. Omtzigt JG, Nau H, Los FJ, Pijpers L, Lindhout D. The disposition of valproate and its metabolites in the late first trimester and early second trimester of pregnancy in maternal serum, urine, and amniotic fluid: effect of dose, co-medication, and the presence of spina bifida. Eur J Clin Pharmacol. 1992;43(4):381-388.

120. Sharony R, Garber A, Viskochil D, et al. Preaxial ray reduction defects as part of valproic acid embryofetopathy. Prenat Diagn. 1993;13(10): 909-918.

121. Lammer EJ, Sever LE, Oakley GP Jr. Teratogen update: valproic acid. Teratology. 1987;35(3):465-473.

122. Bjerkedal T, Czeizel A, Goujard J, et al. Valproic acid and spina bifida. Lancet. 1982;2(8307):1096.

123. Langer B, Haddad J, Gasser B, Maubert M, Schlaeder G. Isolated fetal bilateral radial ray reduction associated with valproic acid usage. Fetal Diagn Ther. 1994;9(3):155-158.

124. Ardinger HH, Atkin JF, Blackston RD, et al. Verification of the fetal valproate syndrome phenotype. Am J Med Genet. 1988;29(1):171-185.

125. Nieto Barrera M, Rufo Campos M, Siliestrom Ribed ML. Partial hydranencephaly in a child coincidental with intrauterine exposure to sodium valproate. Neuropediatrics. 1994;25(6):334-335.

126. Morrow J, Russell A, Guthrie E, et al. Malformation risks of antiepileptic drugs in pregnancy: a prospective study from the UK Epilepsy and Pregnancy Register. J Neurol Neurosurg Psychiatry. 2006; 77(2):193-198.

127. Artama M, Auvinen A, Raudaskoski T, Isojarvi I, Isojarvi J. Antiepileptic drug use of women with epilepsy and congenital malformations in offspring. Neurology. 2005;64(11):1874-1878.

128. Samren EB, van Duijn CM, Christiaens GC, Hofman A, Lindhout D Antiepileptic drug regimens and major congenital abnormalities in the offspring. Ann Neurol. 1999;46(5):739-746.

129. Adab N, Kini U, Vinten J, et al. The longer term outcome of children born to mothers with epilepsy. J Neurol Neurosurg Psychiatry. 2004; 75(11):1575-1583.

130. Meador KJ, Baker GA, Browning N, et al. Foetal antiepileptic drug exposure and verbal versus non-verbal abilities at three years of age. Brain. 2011;134(Pt 2):396-404.

131. Cohen MJ, Meador KJ, Browning N, et al. Fetal antiepileptic drug exposure: adaptive and emotional/behavioral functioning at age 6 years. Epilepsy Behav. 2013;29(2):308-315.

132. Sabril ${ }^{\circledR}$ [package insert]. Deerfield, IL: Lundbeck Inc; 2015.

133. Sorri I, Herrgard E, Viinikainen K, Paakkonen A, Heinonen S, Kalviainen R. Ophthalmologic and neurologic findings in two children exposed to vigabatrin in utero. Epilepsy Res. 2005;65(1-2): $117-120$

134. Zonegran ${ }^{\circledR}$ [package insert]. Teaneck, NJ: Eisai Inc: 2006

135. Kondo T, Kaneko S, Amano Y, Egawa I. Preliminary report on teratogenic effects of zonisamide in the offspring of treated women with epilepsy. Epilepsia. 1996;37(12):1242-1244.

136. National Institute for Health and Care Excellence. Epilepsies: diagnosis and management; 2016. Available from: https://www.nice.org.uk/ guidance/cg137. Accessed June 20, 2016.

137. Cramer JA, Gordon J, Schachter S, Devinsky O. Women with epilepsy: hormonal issues from menarche through menopause. Epilepsy Behav. 2007;11(2):160-178
International Journal of Women's Health

\section{Publish your work in this journal}

The International Journal of Women's Health is an international, peerreviewed open-access journal publishing original research, reports, editorials, reviews and commentaries on all aspects of women's healthcare including gynecology, obstetrics, and breast cancer. The manuscript management system is completely online and includes

\section{Dovepress}

a very quick and fair peer-review system, which is all easy to use. Visit http://www.dovepress.com/testimonials.php to read real quotes from published authors. 